\title{
Evaluasi Kondisi Geologi Teknik dalam Pembangunan Embung
}

\author{
I Gde Budi Indrawan*, Shinta Dwi Novianti, Heru Hendrayana, Doni Prakasa Eka Putra, dan \\ Wahyu Wilopo \\ Departemen Teknik Geologi, Fakultas Teknik, Universitas Gadjah Mada, Jl. Grafika No. 2, Senolowo, \\ Sinduadi, Mlati, Sleman, D.I. Yogyakarta 55284, Indonesia. \\ *igbindrawan@ugm.ac.id
}

Submisi: 22 Mei 2018; Penerimaan: 08 April 2019

\begin{tabular}{l}
\hline Kata kunci: \\
geologi teknik; \\
kesesuaian \\
lahan; \\
pembangunan \\
embung
\end{tabular}

Reywords: detention pond construction; engineering geology; land suitability.

\begin{abstract}
Abstrak Dusun Pucang tersusun oleh material hasil erupsi Gunung Merapi. Relatif tingginya koefisien kelulusan air material penyusun daerah ini menyebabkan air hujan yang jatuh langsung meresap ke bawah permukaan. Evaluasi kondisi-kondisi geologi teknik dilakukan bagi pembangunan embung di daerah ini yang mengalami permasalahan kesulitan pasokan air untuk keperluan masyarakat sehari-hari. Evaluasi dilakukan terhadap hasil pemetaan geologi teknik dengan skala 1:10.000 dan analisis peta kerawanan bencana geologi berskala 1:50.000 dari beberapa peneliti terdahulu. Pemetaan geologi teknik meliputi pemetaan kondisi morfologi dan proses geomorfik aktif, kondisi litologi, keberadaan struktur geologi, dan lokasi sumber air. Hasil evaluasi menunjukkan bahwa lokasi yang diusulkan memenuhi kriteria kesesuaian lahan berdasarkan kondisi morfologi dan proses geomorfik aktif, keberadaan struktur geologi, dan lokasi sumber air, namun tidak memenuhi kriteria kesesuaian lahan berdasarkan aspek litologi dan kerawanan terhadap bencana erupsi Gunung Merapi. Pembuatan lapisan kedap air untuk mencegah rembesan air ke bawah permukaan dan pengerukan endapan pada dasar embung secara berkala disarankan untuk dilaksanakan agar embung dapat tetap berfungsi dengan baik.
\end{abstract}

Abstract Pucang Village was consisted of eruption materials of Merapi Volcano. The relatively high coefficient of permeability of the materials consisting this area caused rainwater to directly infiltrate into the ground. Evaluation of engineering geological conditions was conducted for construction of a detention pond in this area, which had limited water supply for daily activities. The evaluation was conducted on results of a 1:10.000 scale of engineering geological mapping and analyses of 1:10.000 scale of geological disaster maps produced by previous researchers. The engineering geological mapping involved mapping of morphological condition and active geomorphic process, lithological condition, existence of geological structure, and water source location. The evaluation results showed that the proposed location met the land suitability criteria for detention pond construction based on the morphological condition and active geomorphic process, existence of geological structure, and water source location, but did not meet those based on the lithological and vulnerability to Merapi Volcano eruption disaster. Construction of impermeable layer to prevent water seepage into the ground and periodic removal of sediment in the base of the detention pond were suggested to be carried out to keep the detention pond functioning properly. 


\section{PENDAHULUAN}

Beberapa daerah di Indonesia, diantaranya daerah yang terdiri dari endapan pasir lepas hasil erupsi gunung api, mengalami kesulitan pasokan air untuk keperluan sehari-hari. Endapan pasir lepas secara umum memiliki karakteristik drainase yang tinggi sehingga air dapat dengan mudah berinfiltrasi ke bawah permukaan (Holtz \& Kovacs, 1981).

Dusun Pucang, Kabupaten Klaten, Provinsi Jawa Tengah mengalami permasalahan kesulitan pasokan air untuk keperluan sehari-hari masyarakat, baik pada musim kemarau maupun musim penghujan. Daerah ini terletak di lereng Gunung Merapi dan tersusun oleh endapan hasil erupsi Gunung Merapi. Relatif tingginya koefisien kelulusan air material penyusun daerah tersebut menyebabkan air hujan yang jatuh langsung meresap ke bawah permukaan. Masyarakat Dusun Pucang umumnya mengandalkan pasokan air untuk keperluan sehari-hari dari air hujan yang ditampung dalam wadah-wadah dengan volume terbatas sehingga seringkali kekurangan air terutama pada musim kemarau.

Embung sebagai tempat penampungan air dengan volume relatif besar dipertimbangkan sebagai solusi yang paling tepat bagi permasalahan kesulitan air di Dusun Pucang. Lokasi pembangunan embung ditetapkan oleh warga setempat pada lahan yang tidak dimanfaatkan warga. Pembangunan konstruksi, pemilihan lokasi konstruksi harus mempertimbangkan kondisi geologi teknik, antara lain kondisi morfologi, kondisi litologi dan keberadaan struktur geologi, kondisi air tanah, dan kerawanan bencana geologi akibat proses geodinamika, untuk menjamin kelancaran proses pembangunan, dan keberlangsungan konstruksi (Dearman, 1991). Karena pemilihan lokasi pembangunan embung di Dusun Pucang hanya didasarkan pada 
ketersediaan lahan, evaluasi kondisi geologi teknik pada lokasi pembangunan embung yang diusulkan warga perlu dilakukan.

Penelitian ini berisi evaluasi kondisi geologi teknik dalam perencanaan pembangunan embung di Dusun Pucang yang dilaksanakan oleh Departemen Teknik Geologi, Fakultas Teknik, UGM bekerja sama dengan PT. Tirta Investama dalam program pengabdian kepada masyarakat.

\section{PERMASALAHAN}

Masyarakat di Dusun Pucang membutuhkan persediaan air untuk keperluan sehari-hari, baik pada musim kemarau maupun musim penghujan. Pembangunan embung sebagai tempat penampungan air dengan volume relatif besar diharapkan dapat mengatasi permasalahan kesulitan air di daerah ini.

Lokasi pembangunan embung telah diusulkan oleh warga berdasarkan ketersediaan lahan. Namun, evaluasi kondisi geologi teknik belum dilakukan. Evaluasi kondisi geologi teknik diperlukan dalam pemilihan lokasi embung untuk menjamin kelancaran proses pembangunan dan keberlangsungan konstruksi embung.

\section{METODE PENELITIAN}

Evaluasi kondisi geologi teknik bagi kesesuaian lahan pembangunan embung dilakukan terhadap hasil pemetaan geologi teknik dengan skala 1:10.000 dan analisis peta kerawanan bencana geologi berskala 1:50.000 yang disusun oleh Hadisantono dkk. (2002). Pemetaan geologi teknik meliputi pemetaan kondisi morfologi, kondisi litologi, keberadaan struktur geologi, dan lokasi sumber air. Pemetaan kondisi litologi meliputi pemetaan jenis litologi pada singkapan di permukaan dan pengujian laboratorium untuk 
mengidentifikasi dan menentukan klasifikasi keteknikan litologi hasil pengeboran inti pada dua titik di lokasi pembangunan embung. Klasifikasi keteknikan litologi di laboratorium dilakukan menggunakan metode ayakan, hidrometer, dan Casagrande mengikuti prosedur yang dijelaskan dalam standar ASTM D 2487 (ASTM International, 2000a), sedangkan identifikasi dan deskripsi litologi dilakukan berdasarkan prosedur yang dijelaskan dalam standar ASTM D 2488 (ASTM International, 2000b).

\section{HASIL DAN PEMBAHASAN}

\subsection{Kondisi Morfologi}

Pemilihan lokasi embung sebaiknya dilakukan pada daerah dengan morfologi yang landai atau bergelombang dengan kemiringan lereng kurang dari 30\%. Menurut Nuchsin (2011), embung akan cepat penuh oleh adanya sedimentasi akibat erosi apabila dibangun pada daerah dengan kemiringan melebihi 30\%. Hasil pemetaan kondisi morfologi dan klasifikasi satuan geomorfologi yang diusulkan oleh Van Zuidam \& Concelado (1979) menunjukkan daerah penelitian terdiri dari 2 satuan geomorfologi, yaitu satuan lembah gunung api curam dan satuan lereng gunung api bergelombang (Gambar 1).

Satuan lembah gunung api sangat curam memiliki kemiringan lereng berkisar antara 35 hingga $55^{\circ}$ (70 hingga 140\%), sedangkan satuan lereng gunung api agak curam memiliki kemiringan lereng berkisar antara 8 hingga $16^{\circ}$ (15 hingga $30 \%$ ). Karena lokasi pembangunan embung berada pada daerah dengan kemiringan lereng yang relatif aman terhadap sedimentasi, lokasi yang diusulkan masyarakat memenuhi kriteria kesesuaian kondisi morfologi, terutama kemiringan lereng, bagi pembangunan embung (Gambar 2). 


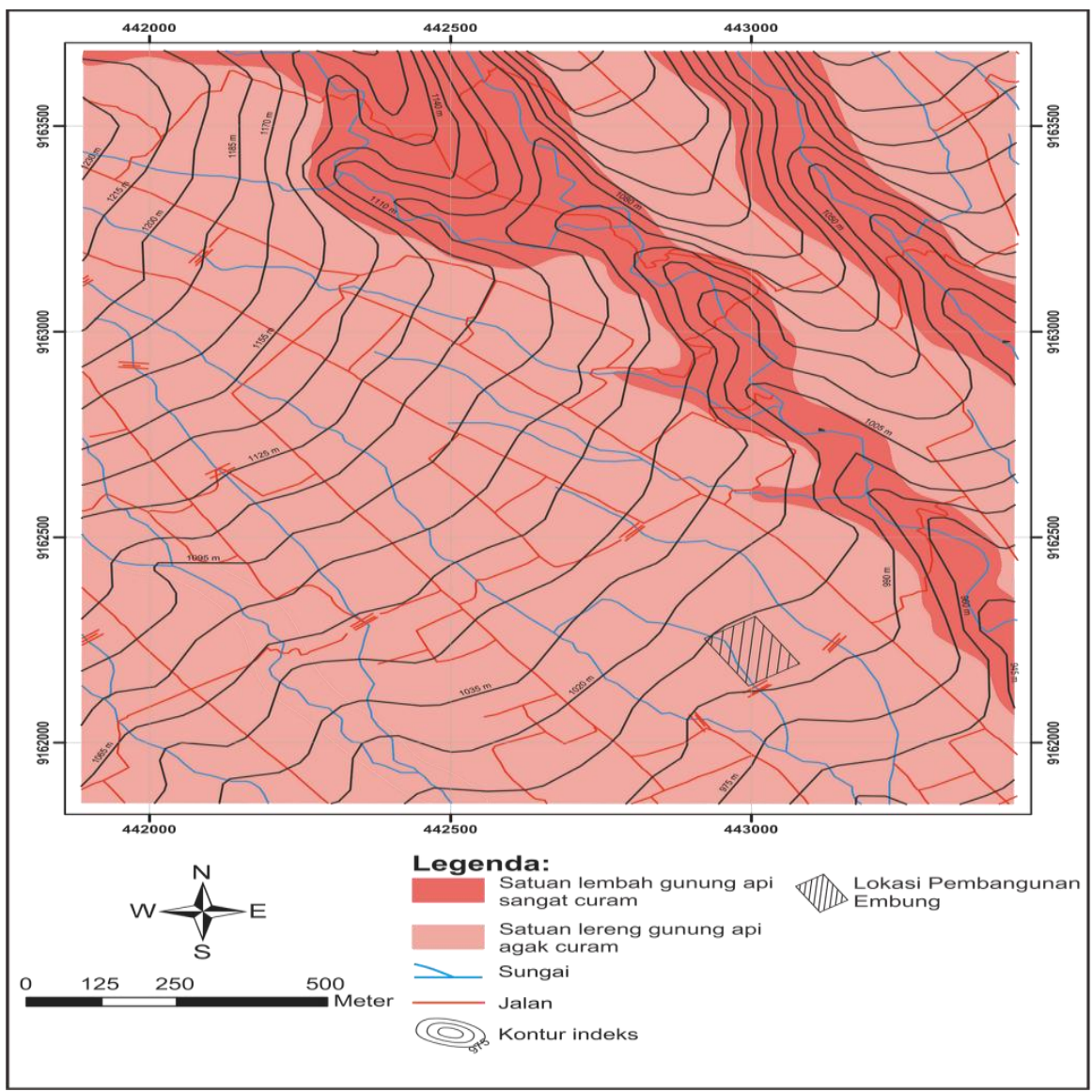

Sumber: Data primer diolah (2015)

Gambar 1. Peta Geomorfologi Dusun Pucang

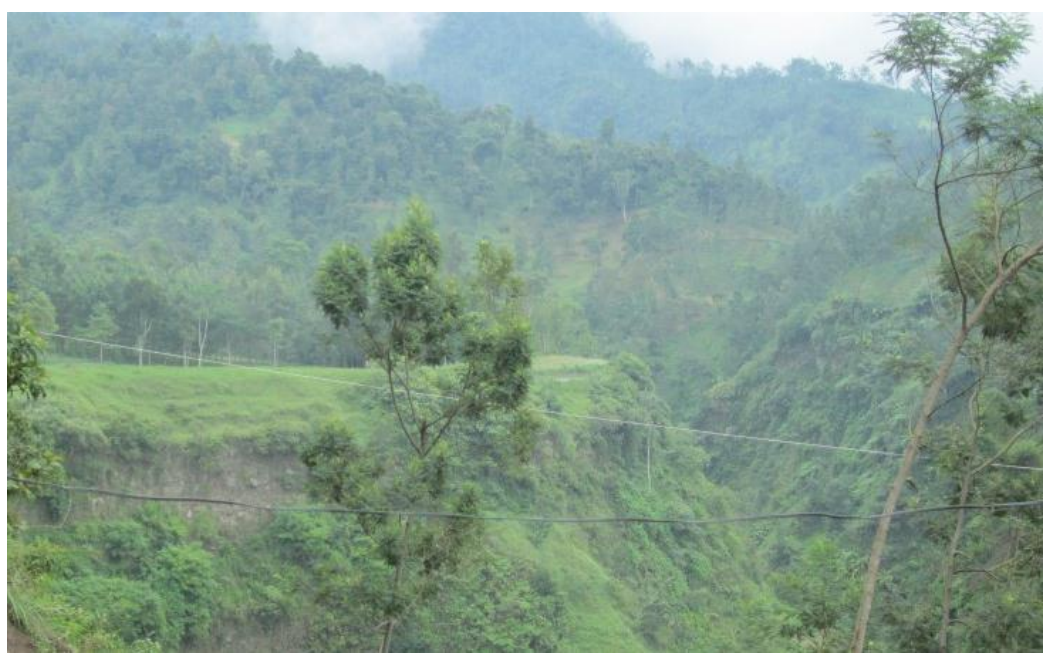

Sumber: Data primer diolah (2015)

Gambar 2. Morfologi Lembah dan Lereng Gunung Api di Dusun Pucang 


\section{2. $\quad$ Kondisi Litologi dan Keberadaan Struktur Geologi}

Litologi penyusun daerah penelitian (Gambar 3) meliputi endapan breksi laharik dan endapan pasir lanauan (Gambar 4 dan Gambar 5). Mengacu pada peta geologi regional Gunung Merapi (Wirakusumah dkk., 1989), endapan breksi laharik dan endapan pasir lanauan yang terdapat dalam lokasi penelitian termasuk dalam Endapan Gunung Merapi Muda. Endapan breksi laharik (Gambar 4) melampar dan mengisi celah pada lembahlembah gunung api, sedangkan endapan pasir lanauan melampar pada bagian lereng gunung api.

Lokasi pembangunan embung terletak pada endapan pasir lanauan. Endapan pasir lanauan (Gambar 5) bersifat lepasan dan secara megaskopis bewarna abu-abu kecokelatcokelatan, ukuran butir lanau - kerakal, bentuk butir angular-subangular, sortasi baik, tersusun oleh fragmen andesit serta material sedimen berukuran pasir dan lanau.

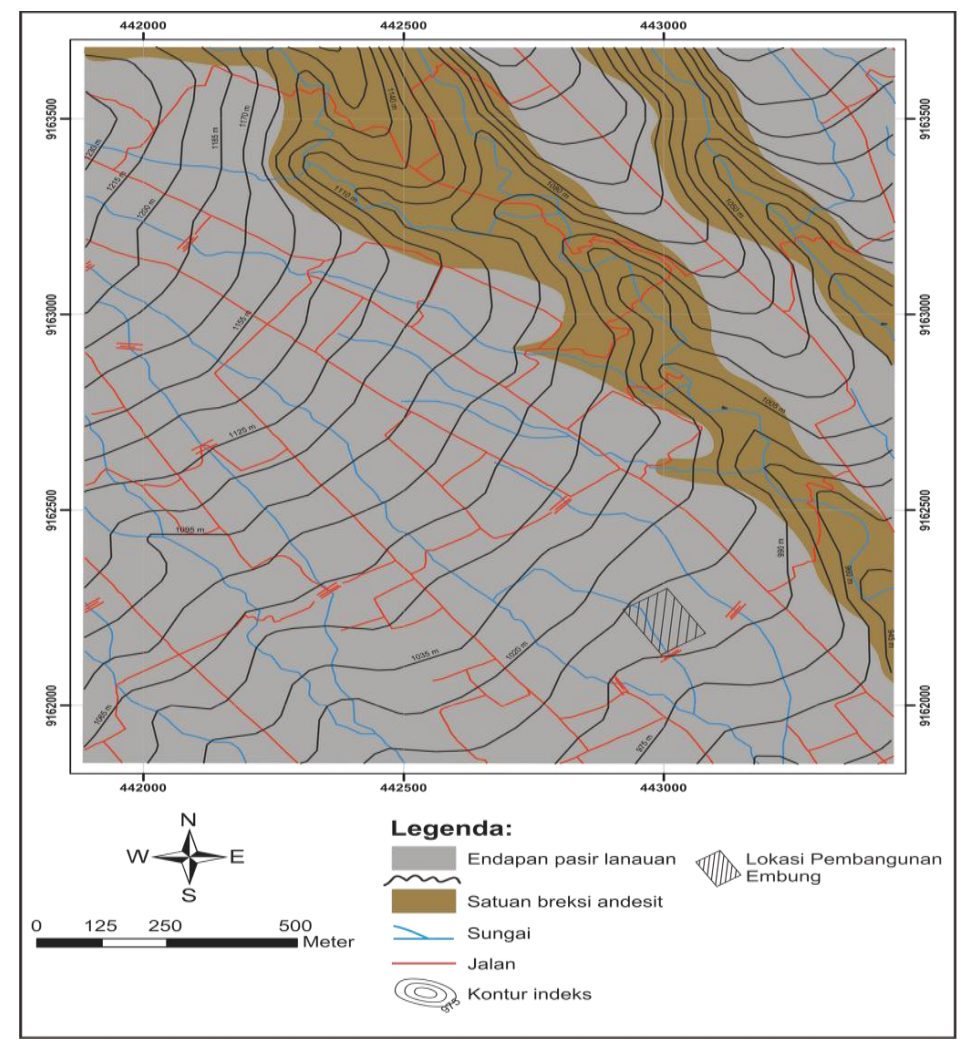

Sumber: Data primer diolah (2015)

Gambar 3. Peta Geologi Daerah Penelitian 
Berdasarkan pengujian distribusi ukuran butir, endapan pasir lanauan tersusun oleh material berupa pasir lanauan (SM) dan lanau pasiran (ML). Mengacu pada klasifikasi kesesuaian material bagi konstruksi dalam Budhu (2011), kedua endapan di lokasi pembangunan ini cukup baik jika digunakan sebagai material konstruksi embung, namun buruk apabila digunakan sebagai pondasi suatu konstruksi. Dengan demikian, lokasi yang diusulkan masyarakat kurang memenuhi kriteria kesesuaian lahan bagi pembangunan embung berdasarkan aspek kondisi litologi. Pekerjaan rekayasa berupa pembuatan lapisan kedap air diperlukan untuk mencegah rembesan air yang ditampung dalam tubuh embung ke bawah permukaan.

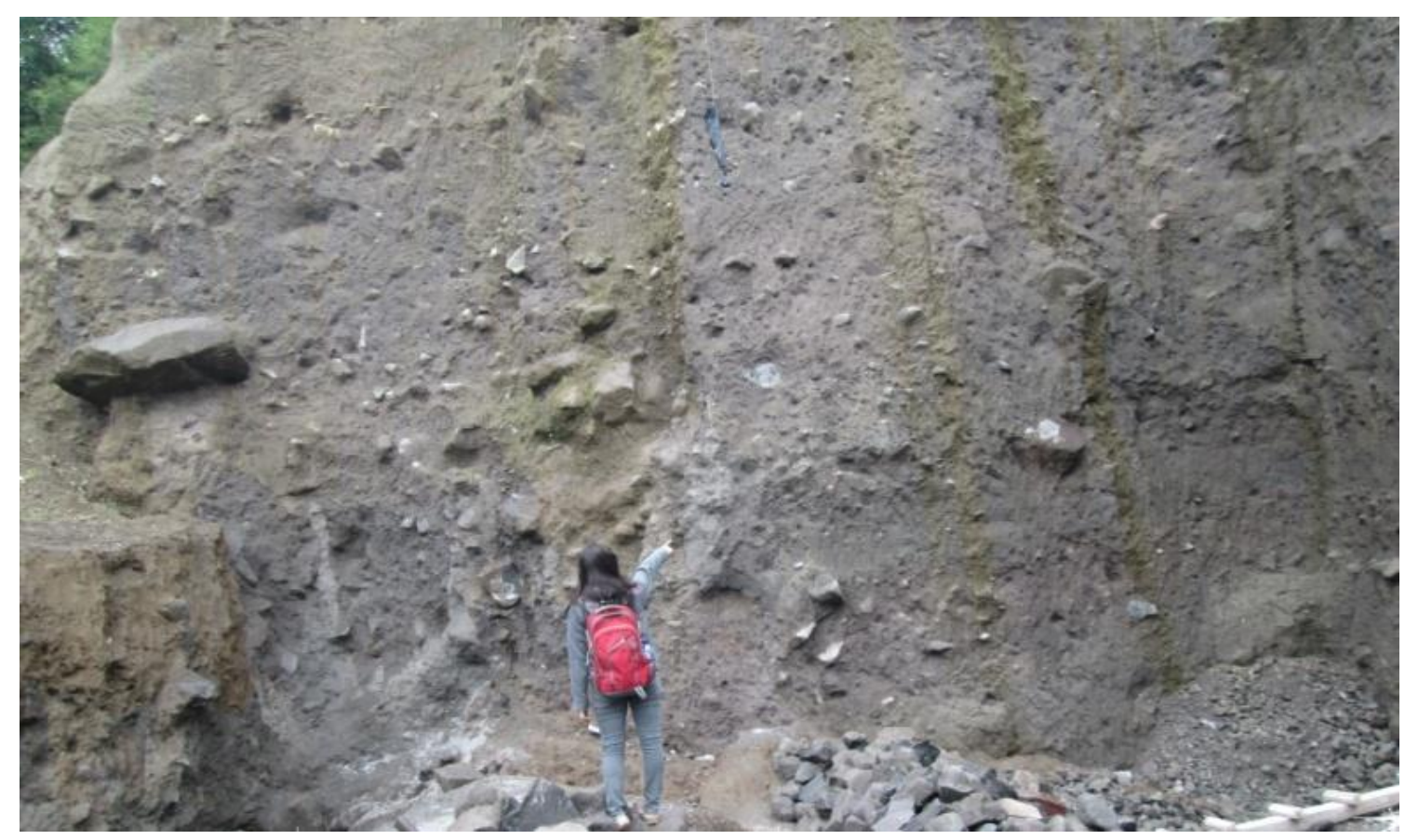

Sumber: Data primer diolah (2015)

Gambar 4. Kenampakan Litologi di Dusun Pucang: Endapan Breksi Laharik 


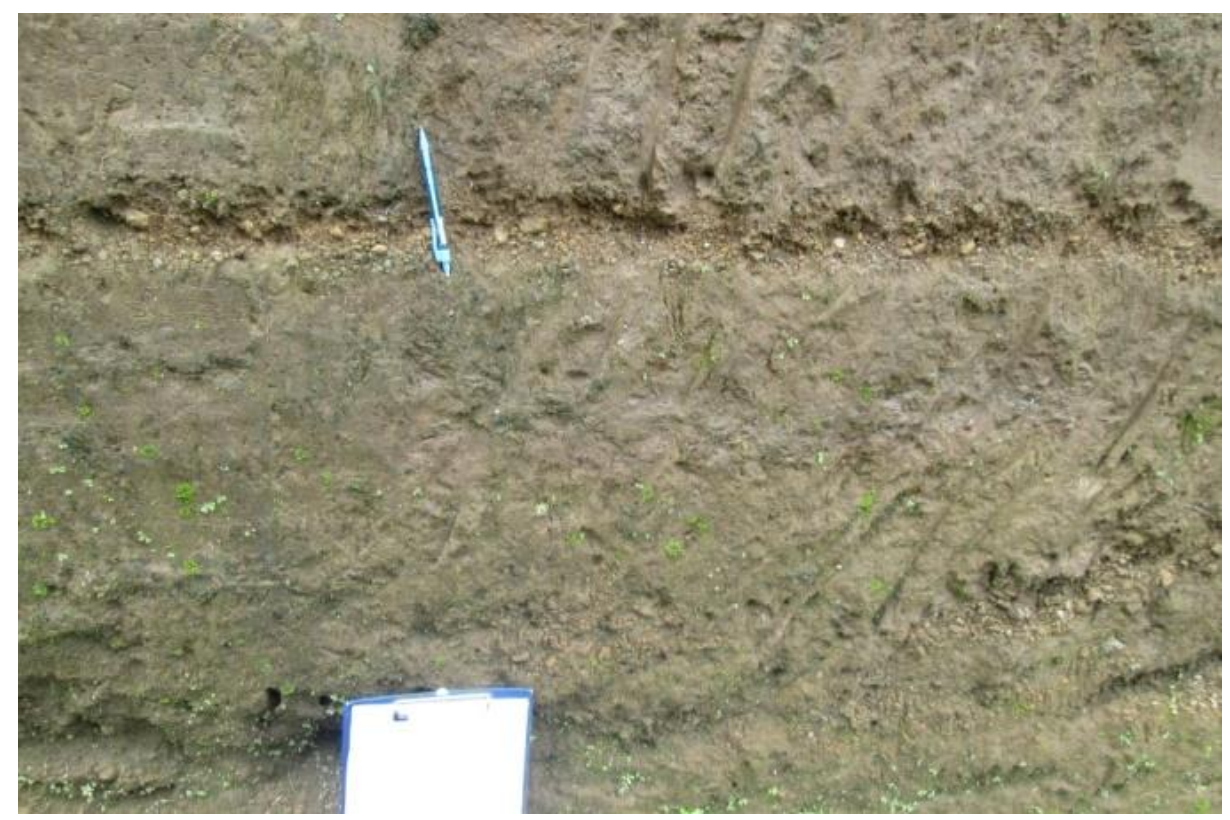

Sumber: Data primer diolah (2015)

Gambar 5. Kenampakan Litologi di Dusun Pucang: Endapan Pasir lanauan.

Hasil pemetaan di permukaan (Gambar 3) menunjukkan daerah penelitian di Dusun Pucang tidak berada pada zona struktur geologi. Dengan demikian, lokasi pembangunan embung memenuhi kriteria kesesuaian lahan bagi pembangunan embung berdasarkan aspek keberadaan struktur geologi.

\subsection{Kerawanan Bencana Geologi Akibat Proses Geodinamika}

Bencana geologi yang paling berpotensi terjadi di lereng Gunung Merapi adalah bencana akibat letusan Gunung Merapi. Dalam Peta Kawasan Rawan Bencana Gunung Merapi yang disusun oleh Pusat Vulkanologi dan Mitigasi Bencana Geologi Badan Geologi Kementerian ESDM (Hadisantono dkk., 2002) disebutkan potensi letusan Gunung Merapi meliputi awan panas (pyroclastic flow), hujan abu lebat (pyroclastic fall), lontaran batu (pijar), serta lahar. Newhall dkk. (2010), mendefinisikan awan panas sebagai material hasil erupsi yang berasal dari guguran lava, terakumulasi pada bagian 
lereng Gunung Merapi, dan bergerak menuruni lereng dengan aliran turbulensi. Hujan abu dan lontaran batu (pijar) merupakan produk Gunung Merapi yang dilontarkan ke udara saat terjadi erupsi. Lahar terbentuk apabila material hasil erupsi Gunung Merapi terpindah menuruni lereng melalui celah sungai oleh hujan.

Analisis terhadap Peta Kawasan Rawan Bencana Gunung Merapi menunjukkan lokasi pembangunan embung berada pada Kawasan Rawan Bencana II dengan potensi bahaya berupa lontaran batu (pijar) berukuran $>2 \mathrm{~mm}$ serta hujan abu lebat. Hujan abu lebat di lokasi pembangunan embung saat terjadi letusan Gunung Merapi dapat mempercepat terjadinya sedimentasi di dalam tubuh embung. Dengan demikian, lokasi yang diusulkan oleh masyarakat kurang memenuhi kriteria kesesuaian lahan bagi pembangunan embung berdasarkan aspek kerawanan bencana Gunung Merapi. Namun, dampak dari erupsi Gunung Merapi dapat dimitigasi dengan melakukan perawatan pasca-erupsi tehadap tubuh embung. Apabila tubuh embung mengalami pendangkalan akibat banyaknya endapan hasil erupsi Gunung Merapi, maka dapat dilakukan pengerukan secara berkala terhadap endapan di dalam tubuh embung.

\subsection{Lokasi Sumber Air}

Hasil pemetaan sumber air di sekitar lokasi pembangunan embung (Gambar 6) menunjukkan bahwa dua sumber air, yaitu mata air Jeromah yang berada sekitar $3 \mathrm{~km}$ di bagian barat laut dan parit yang berada di bagian barat lokasi pembangunan embung, berpotensi untuk dimanfaatkan sebagai pengisi embung, selain air hujan. Oleh karena itu, lokasi yang diusulkan oleh masyarakat memenuhi kriteria kesesuaian lahan bagi pembangunan embung berdasarkan aspek sumber air. 


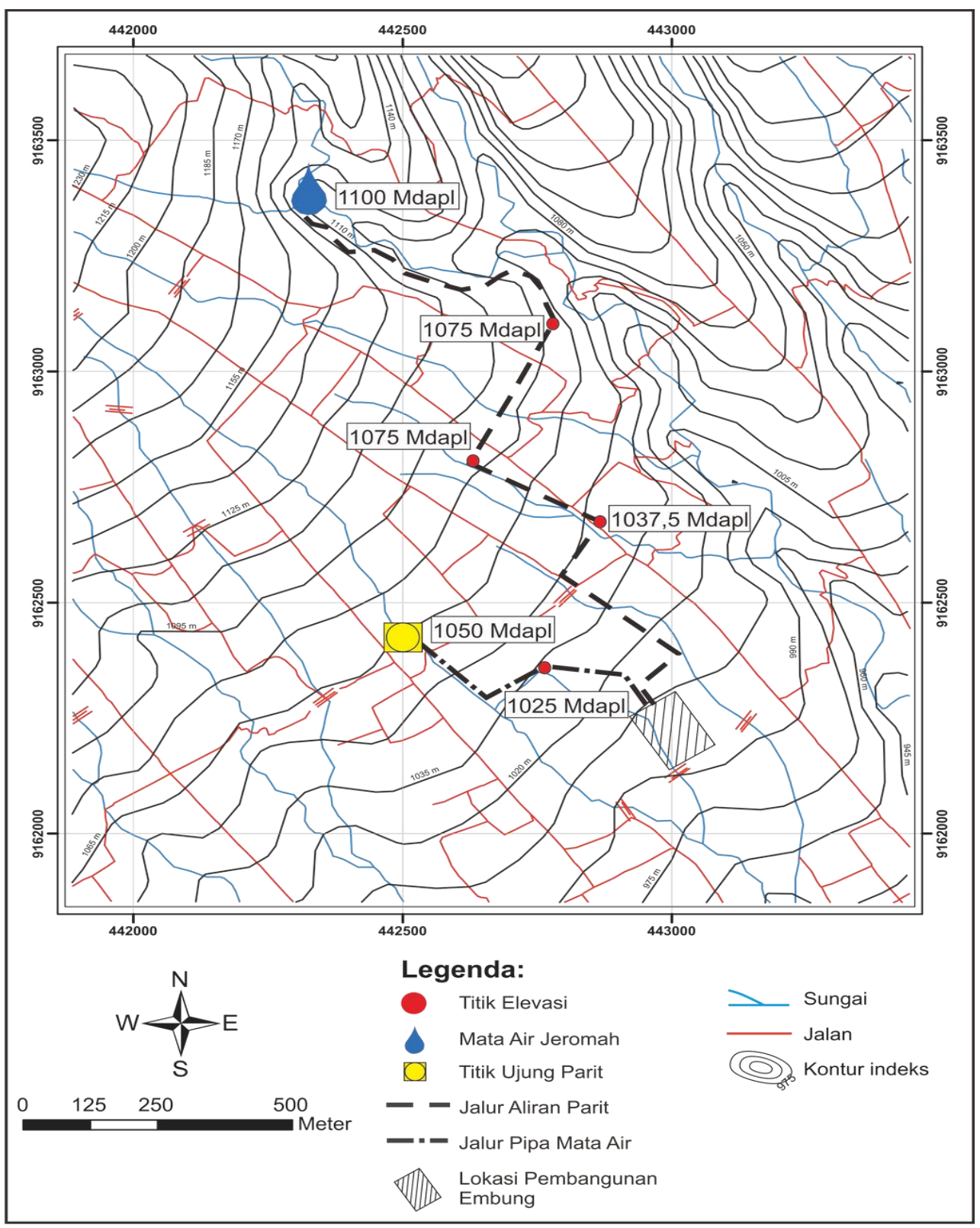

Sumber: Data primer diolah (2015)

Gambar 6. Peta Lokasi Sumber Air di Sekitar Lokasi Pembangunan Embung pada Dusun Pucang

\section{KESIMPULAN}

Evaluasi geologi teknik terhadap kesesuaian lahan pembangunan embung di Dusun Pucang menunjukkan bahwa lokasi yang diusulkan masyarakat memenuhi kriteria kesesuaian kondisi morfologi, keberadaan struktur geologi, dan lokasi sumber air, namun tidak memenuhi kriteria kesesuaian aspek litologi dan kerawanan bencana erupsi 
Gunung Merapi. Beberapa pekerjaan rekayasa antara lain pembuatan lapisan kedap air untuk mencegah rembesan air dalam tubuh embung ke bawah permukaan dan pengerukan secara berkala terhadap endapan di dalam tubuh embung pasca-erupsi Gunung Merapi disarankan untuk dilaksanakan agar embung dapat tetap berfungsi dengan baik.

Penelitian berikutnya terkait kestabilan tubuh embung terhadap gempa perlu dilakukan berdasarkan pertimbangan kondisi endapan pasir lanauan yang bersifat lepas dan rentan mengalami likuifaksi. Demikian juga penelitian terkait kualitas air perlu dilakukan untuk menjamin air yang ditampung di dalam embung memenuhi standar baku mutu peruntukkannya.

\section{DAFTAR PUSTAKA}

ASTM International. (2000a). ASTM D 2487. Standard Practice for Classification of Soils for Engineering Purposes (Unified Soil Classification System).

ASTM International. (2000b). ASTM D 2488, Standard Practice for Description and Identification of Soils Purpose (Visual-Manual Procedure).

Budhu, M. (2011). Soil Mechanics and Foundations. John Wiley \& Sons, Inc.

Dearman, W.R. (1991). Engineering Geological Mapping. Oxford: ButterworthHeinemann Ltd.

Hadisantono, R.D., Andreastuti, M.Ch.S.D., Abdurachman, E.K., Sayudi, D.S., Nurnusanto, I., Martono, A., Sumpena, A.D., \& Muzani, M. (2002). Peta Kawasan Rawan Bencana Gunung Merapi, Jawa Tengah dan Daerah Istimewa Yogyakarta Pusat Vulkanologi dan Mitigasi Bencana Geologi Badan Geologi Kementerian ESDM. 
Holtz, R.D. \& Kovacs, W.D. (1981). An Introduction to Geotechnical Engineering. Prentice-Hall.

Newhall, C.G., Bronto, S., Alloway, B., Banks, N.G., Bahar, I., del Marmol, M.A., Hadisantono, R.D., Holcomb, R.T., McGeehin, J., Miksic, J.N., Rubin, M., Sayudi, D.S., Sukhyar, R., Andreastuti, M.Ch.S.D., Tilling, R.I., Torley, R., Trimble, D., \& Wirakusumah, A.D. (2000). 10,000 Years of Explosive Eruptions of Merapi Volcano, Central Java: archeological and modern implications: Journal of Volcanology and Geothermal Research. Elsevier.

Nuchsin, P. (2011). Pedoman Pelaksanaan Proyek. Direktorat Pengelolaan Air Irigasi Dirjen Prasarana dan Sarana Pertanian Kementerian Pertanian. Jakarta.

Van Zuidam, R.A. \& Concelado, F. I. (1979). Terrain Analysis and Classification Using Aerial Photographs, Netherland: ITC, Enschede.

Wirakusumah, A.D., Juwarna, H., \& Loebis, H. (1989). Peta Geologi Gunungapi Merapi, Provinsi Daerah Istimewa Yogyakarta dan Jawa Tengah, Pusat Vulkanologi dan Mitigasi Bencana Geologi Departemen Energi dan Sumber Daya Mineral. Skala 1:50.000. 